\title{
ANALYSIS OF TYPES AND REASONS INDONESIAN-ARABIC CODE-SWITCHING-BY SOCIOLINGUISTICS APPROACH
}

\author{
Pratiwi Sakti
}

Department of Psychology, Faculty of Psychology, Universitas Teknologi Sumbawa

${ }^{*}$ Corresponding Author email: Pratiwi.sakti@uts.ac.id

\begin{tabular}{|c|c|}
\hline & Abstract \\
\hline $\begin{array}{l}\text { Accepted: } \\
\text { June } 2020 \\
\text { Published: } \\
\text { july } 2020 \\
\text { Keywords: } \\
\text { code-switching, } \\
\text { discourse, inter- } \\
\text { sentencial c-s, } \\
\text { syntactic word } \\
\text { category, habit. }\end{array}$ & $\begin{array}{l}\text { The background of this research is to Investigate the types and reasons of Indonesian- } \\
\text { Arabic code-switching in Indonesian community, especially in the Arabic Department. It } \\
\text { aims at investigating the types, syntactic categories, and reasons of Indonesian-Arabic } \\
\text { code-switching. The writer uses both quantitative and qualitative methods. It is counting } \\
\text { and analysing the discourses between lecturer and students in the class. The population is } \\
80 \text { students and the sample is limited on } 34 \text { students who have educational background } \\
\text { from Islamic institutional school. The length of meeting is } 138.92 \text { minutes with } 35 \text { topic } \\
\text { discourses then sorted becoming } 50 \text { corpuses. The result of this study shows that in term } \\
\text { of types of Indonesian-Arabic code-switching inter-sentencial is the most dominant of all } \\
\text { types code-switching. It comprises } 50 \% \text { of the data. In term of Arabic syntactic word } \\
\text { categories, noun occupies the first level. It comprises with } 63 \text { nouns with } 38.41 \text { percents. } \\
\text { In term of reason, repetition for clarification and emphasize the message are the most } \\
\text { dominant than others. It comprises } 20-83 \% \text {. The result of questionnaires shows that habit } \\
\text { is the dominant reason of code-switching happens. The impact of this research is used for } \\
\text { the language teacher to allow their students switching the national to local language, vice } \\
\text { versa, to absolve students expressing themselves through language learning methods } \\
\text { using localization context. }\end{array}$ \\
\hline
\end{tabular}

\section{INTRODUCTION}

In multi-lingual society as Indonesia, a speaker tries to choose a language when the speaker interacts with people. There are several languages in Indonesia, such as vernaculars, Indonesian, English and Arabic. Generally, vernaculars as mother tongue, Indonesian as language of nation or as second language, English and Arabic as foreign languages. In Makassar, there are several Moslems are interested to study Arabic because it is language of Islam and has been well-known in entire the world (Chaer, et al., 2010: 16)

Makassar as one of students' cities has made up several speech communities, English speech community, Makassar-Malay speech community, Arabic-speech community, Japanese-Indonesian speech community, each of it is shaped based on what goal they want to achieve. In Arabic-speech community, is not merely taught inside the class come up with several goals, for instance religious reason, learning goal, and lingua-franca goal. The writer felt interested in to dig up more on learning goal. Since Arabic based on preliminary interview said "it is difficult to learn and difficult to remember". The writer interested in what aspect triggers them to learn and what syntactic barriers make them unable to remember it. Therefore, it needs several strategies to deliver better understanding for them in Arabic learning.
The writer focused on Arabic Department in Hasanuddin University which it is representative for the aims of the research. Therefore, the writer decided conducting research on the phenomena of Indonesian-Arabic code-switching between lecturers and students in the Arabic Department's class. The objective of this study is to investigate the types of Indonesian-Arabic code-switching performed by lecturers and students in the classroom, the Arabic syntactic words categories in Indonesian-Arabic code-switching, then the reason of the lecturers and students switch their code into

Arabic in the classroom. The significance of this research is the reference enrichment in sociolinguistics field concerning in code-switching.

This research contributes as one of sociolinguistics reference. Particularly, to analyse

the Arabic syntactic word categories in codeswitching and bilingualisms' or multilingualisms' reasons to switch their code into the second language. The study focuses on discourses-between lecturers and students in Arabic Proficiency

(Kemahiran Bahasa Arab) class. The class was taught by Muhammad Ridwan in two meetings for 138.92 minutes with 44 students. The discourse was carried out by classroom activities with 33 respondents as sample of research by several criteria as elaborated down below. 


\section{THEORETICAL BACKGROUND}

\section{Sociollingualism}

The first definition of sociolinguistics is taken from Hudson (1980), who stated that sociolinguistics is the study of language in relation to society. The second definition is from Fishman in Chaer and Agustina (2004: 3) stated that sociolinguistics is the study of the characteristics of language varieties, the characteristics of their functions, and the characteristics of the speaker as these three constantly interact and change within a speech community.

When one enters in particular speech community, e.g. Bimanese whom lives in suburban, and getting married with Javanese woman, the woman will be unavoidable to have marriage by the culture. Bimanese language is a part of the way of Bimanese life which is similar to eating habit, marriage process and ritual or usually the couple shares their culture together. In addition, it is not only intercultural marriage, but also cross-culture communication which leads to switching between two different languages while she interacts with her in laws family.

The characteristics of the speaker change by context, change by situation, change by the capability of the speaker in speaking the language and change by existence of the third person in turn taking mechanism process or real discourse at the table. This study found that the example of the characteristic of the language-variety was when the lecturer in class spoke Arabic based on Arabic dialect then he changed his language variety in Bone dialect although he still spoke Arabic. This situation is similar to Blom and Gumperz (1972) stated in Yassi and Hakim (2003) found that when the Norwegian lecturers delivered the course with official standard form, they shifted to regional Norwegian dialect in discussion activity within the students.

\section{Billingualism}

When the topic of discussion is sociolinguistics, it means the discussion concerning interaction of two people using two different languages. Hamer and Blank have pointed out the definition of Sociolinguistics as many students stated in their journals. According to Hamers and Blanc (1984: $45)$, the state of a linguistic community in which two languages resulted that two codes could be used in the same interaction and bilingual.
In addition, Gumperz (1971: 22) also mentioned that bilingual people usually use their own idioms for in-group communication and the common language for their interaction and communication with outsiders. When it turns to bilingualism, it turns to discussion concerning in multilingualism, which clearly indicates more than two different languages exist in society.

\section{Multilingualism}

Multilingual appears because there is multicultural society, each society determines their own culture. Alike those definitions, the situation is common and easily found out, such as in working places, mosques, churches, or online and offline markets. This situation as similar as described by Wardhaugh (1987: 95) gave an explanation concerns in the use of several languages by a society, he stated that "In many parts of the world, it is just a normal requirement of daily living that people speak several languages for some purposes, such as communication with family at home, trading, and contacting with the people from other countries of wider social or political organization. These various languages are usually acquired naturally and unself consciously.

\section{Code}

Code according to Stockwell (2002:8-9) is a symbol of nationalism that is used by people to speak or communicate in a particular language, dialect, register, accent, or style on different occasions and for different purposes. Similarly, Wardaugh (1986:101) also mentioned that a code can be defined as a system used for communication between two or more parties used on any occasions.

\section{Code Switching and Code Mixing}

Code in this journal means language whether it is word, phrase, clause, or sentence itself. Those codes can be a word of Arabic, a phrase of Indonesian, or a sentence of Arabic. According to Hudson (1980:56), code-switching in which a single speaker uses different varieties at different times in term of situation. Variety means language in different level of syntactic categories. For Example, someone uses Indonesian and then he suddenly switches his dialect into Bonese in a discourse because his friend comes from Bone, he switches to Bonese to changes the familiar situation. Similarly, Valdes-Fallis (1977) in Yassi and Hakim (2003: 35) defined that code switching as the use of two 
languages simultaneously or interchangeably. This implies some degrees of competence in the two languages even if bilingual fluency is not stable yet. The notion of code-switching defined by ValdesFallis is clearer and more suitable with the situation faced by writer in the field.

Poplack (1980) in Yassi and Hakim (2002: 120) has divided code-switching into three categories:

1. Tag switching involves the insertion of a tag in oa language into an utterance which is otherwise entirely in the other language, e.g. You know, I mean. They may be easily at a number of points in a monolingual utterance without violating syntactic rules (Romaine, 1991:112). This is also called as emblematic switching or 'extra-sentential' switching.

The term is usually called as an extra- sentencial switching as stated in Romaine (1991: 112) in Yassi and Hakim (2003 :45), it can be inserted quite freely into the sentences without having to obey syntactic constraint or violating syntactic rules. Based on writer's preliminary observation in Arabic: syukran (thank you), khalas ba'da dzālik (after that), ha hunā (ok). Tag-switching also could be said as discourse markers, such as well, ok, all right, interjection and affirmative/negative particles (e.g. yes or no).

2 Inter-sentential of code-switching in Romaine (1991) pointed out that intrasentential switching involves arguably, the greatest syntactic risk, and may be avoided by all but the most fluent bilingual. Switching of different types occurs within the clause or sentence boundary.

This example from Tok Pisin-English stated in Yassi and Hakim (2002): "What's so funny? Come, be good. Otherwise, yu bai go long kot" "What's so funny? Come, be good. Otherwise, you'll go to court"

3. Inter-sentential switching involves a switch at a clause or sentence boundary, where is a clause or sentence is in one language or another.

This example from Puerto Rican bilingual Spanish/English speech is given by Poplack (1980), such as, "Sometimes I'll start in English y termino in espanol" (Sometimes I'll start a sentence in English and finish it in Spanish).
It means that the switch occurs between sentence boundaries. The speaker utters one sentence in one language, and he switches to another sentence in another language. Yassi (2003) in Fadhilah (2010) added the other categories of code switching:

1. Inter-clausal, the switching occurs outside the clause boundary as in: "Jadi ini untuk Nick?” (This is for you, Nick?) (Rasmi, 2006).

2. Intra clausal, the switching takes place within the clause boundary as in the example, "Ah, klo gini nih, focus selepas dia jatuh apa impact daripada ini." (Ah, if it's like this, focus after she falls, then what is the impact afterwards) (Pidarwarty, 2005).

Furthermore, Yassi and Hakim (2003) divided the intra-clausal switching into:

a Intra-phrasal, which occurs within the phrase boundary as in the example: "Bagaimana bisa bagus kalo political willnya kacau." (How could it be good if the political will messy?) (Yassi and Hakim, 2003).

b. Intra-lexical, which take place within a word boundary, as in: "Yang sekarang didiscuss what is other gender process." (Something which is discussed now what is othe gender process) (Pidarmawarty, 2005)

\section{The Functional Approach of Code-Switching}

1. Situational function of code-switching

2. Social function of switching

3. Metaphorical function of code-switching

According to Hoffman (1991: 116) stated in Cakrawarti (2011: 17), there is a number of reasons for bilingual or multilingual person to switch or mix their languages. Those are:

1. Talking about a particular topic.

2. Quoting somebody else.

3. Being emphatic about something (express solidarity).

4. Interjection (inserting sentence fillers or sentence connectors).

5. Repetition used for clarification.

6. Intention of clarifying the speech content for interlocutor.

7. Expressing group identity. 
8. To soften or strengthen request or command.

9. Because of real lexical need.

10. To exclude other people when a comment is intended for only a limited audience.

\section{RESEARCH METHODS}

\section{Field Research}

The research held in classes of Arabic Department for a month, specifically in Kemahiran Bahasa Arab (The Arabic Proficiency) classes. The steps of field research are illustrated as follows:

\section{a. Observation}

Observation is way of gathering data by watching behaviour, events, or noting physical characteristics in their natural setting. Observations can be overt (everyone knows they are being observed) or covert (no one knows they are being observed and the observer is concealed) (ETA, 1:2008).

b. Recording

Recording is one of steps to collect the pure discourse between lecturers and students. The writer had submitted 35 topic discourses for 138.92 minutes in two meetings.

c. Questionnaires

Questionnaire is an instrument which is used by the writer to explore the data yet appear in direct observation. This is significant because there are several data yet appears in observation but will appear in questionnaires.

\section{Analysis Methods}

1. Sort discourses which are including the Indonesian-Arabic C-S only then tabulated it.

2. After tabulating the data, then the writer counts the percentage of corpuses, using Gay's formulation as Fadhilah (2010):

$$
\frac{\text { Number of Corpuses }}{\text { Namman of mannman }} \times 100
$$

3. Analysing the questionnaires.

\section{Population and Sample}

The population in this study was the first semester students in Kemahiran Bahasa Arab course on Wednesday and was taught by Muhammad Ridwan at Hasanuddin University, Makassar.
The study applied purposive sampling method for collecting data which is recorded from discourses between lecturer and students in the Arabic department classroom activities. The subject of research was limited in 33 students from pesantren, MAN then lecturer sorted in 50 corpuses from 35 topic discourses in two meetings for 138,92 minutes.

\section{FINDING AND DISCUSSIONS}

The Analysis of Indonesian-Arabic C-S (Indonesian as Source Language)

The lecturer has Arabic advanced level as bilingual, Arabic morphology, and syntactic words as inflectional words give chance to the speaker in choosing sentence than clause and phrase. As seen in corpuses katabtu (I wrote), ji'tu, nadzartu (I saw). The verb joined by subject ease the speakers to utter sentence than clause although the word hear simple, but the listener can understand the sentence as "Katabtu fi al-lughati al-'arabiyyah" I wrote Arabic, for an Arabian, to produce sentence is quite easy i.e., he/she just add "maf'ulun bihi" or object after verbal phrase as above, $t u$ translated into I, alike tulisku in Indonesian.

\section{The Types of Indonesian-Arabic C-S}

Table 1. Types Indonesian-Arabic code-switching.

\begin{tabular}{lll}
\hline No Types & $\begin{array}{c}\text { Number of Percentage \% } \\
\text { Corpuses }\end{array}$
\end{tabular}

\begin{tabular}{llcc}
\hline $\mathbf{1}$ & IntSen & 25 & 50 \\
2 & IntraPhra & 8 & 16
\end{tabular}

$\begin{array}{cccc}\mathbf{3} & \text { IntraSen } & 5 & 10 \\ 4 & \text { IntraLex } & 4 & 8\end{array}$

$\begin{array}{llll}5 & \text { IntCla } & 3 & 6 \\ 6 & \text { Tag } & 3 & 6\end{array}$

\begin{tabular}{llll}
7 & IntraCla & 2 & 4 \\
\hline
\end{tabular}

The table is ordered based on the highest score of Indonesian-Arabic types C-S. According to writer's finding, it can be revealed that intersentencial is the most occurred data on the corpuses. As seen on the table above. Inter-sentencial is the most occurred, it can be explained as Arabic has 
sentence pattern as follows. SVO, subject, verb, and object: Sa-adzhabu ila suwky (I am going to market). VSO, verb, subject, object: katabtu risalatan (wrote I letter-I wrote a letter).

Table 2. The Arabic Syntactic Words Categories

\begin{tabular}{lllc}
\hline No & $\begin{array}{c}\text { Arabic Syntactic } \\
\text { Words Categories }\end{array}$ & Token & \% \\
\hline $\mathbf{1}$ & Noun Phrase & 53 & 32.32 \\
$\mathbf{2}$ & Verb Phrase & 28 & 17.07 \\
$\mathbf{3}$ & Noun & 63 & 38.41 \\
$\mathbf{4}$ & Verb & 8 & 4.88 \\
$\mathbf{5}$ & Adverb & 8 & 4.88 \\
$\mathbf{6}$ & Noun Clause & 4 & 2.44 \\
$\mathbf{7}$ & Verb Clause & 0 & 0 \\
\hline
\end{tabular}

In term of Arabic syntactic words, noun is the most dominant segment switching which is used by the lecturer and students in Indonesian-Arabic codeswitching, then noun phrase, verb phrase, verb, adverb, noun clause in order. The domination of noun than verb in the segment switching is not apart from the definition of noun as the free word in Arabic.

Noun is not bounded by sequence of tense on the contrary, verb in Arabic have sequence of tenses, such as past tense or perfective aspect ( $f i^{\prime} i l$ mãdi), present tense or imperfective aspect (fi'il mudhori). Both of these time sequences have risk when the speaker chooses words of it and it completely changes the pattern of the sentence, such as the speakers must have great capability in nahwu (syntac) and shorof (morphology). See corpus 27.

Table 3. The Reason of Indonesian-Arabic CodeSwitching

\begin{tabular}{clcc}
\hline No & Reason & Corps & \% \\
\hline $\mathbf{1}$ & Interjection & 4 & 8 \\
$\mathbf{2}$ & Topic have been talked & 5 & 10 \\
$\mathbf{3}$ & Repetition to clarify & 10 & 20 \\
$\mathbf{4}$ & To native & 8 & 16 \\
\hline
\end{tabular}

\begin{tabular}{|c|c|c|c|}
\hline 5 & To soften & 2 & 4 \\
\hline 6 & To exclude & 1 & 2 \\
\hline 7 & $\begin{array}{l}\text { Intention clarify speech } \\
\text { content for interlocutor }\end{array}$ & 8 & 16 \\
\hline 8 & $\begin{array}{l}\text { Expressing group } \\
\text { identity }\end{array}$ & 1 & 2 \\
\hline
\end{tabular}

\begin{tabular}{|llll}
9 & To gain attention & 1 & 2 \\
\hline 10 & To quote & 7 & 14 \\
\hline 11 & $\begin{array}{l}\text { Play with arabic } \\
\text { phoneme }\end{array}$ & 1 & 2 \\
\hline 12 & Unidentified & 2 & 4 \\
\hline
\end{tabular}

Based on the table, repetition to clarify is the most occurring in the reason of Indonesian-Arabic c-s. It is explained as repetition is the vital reason of c-s usually happen to the passive, bilingual or multilingual speaker. It is because speaker with beginner, intermediate, and advance level approve Arabic as foreign language not second language. Therefore, repetition is very important to assert aims between two speakers.

Questionnaires Analysis

Table 4. Respondents' Regions

\begin{tabular}{clcc}
\hline No. & \multicolumn{1}{c}{ Region } & R & \% \\
\hline $\mathbf{1}$ & South Sulawesi & 22 & 64.71 \\
$\mathbf{2}$ & West Sulawesi & 5 & 14.71 \\
$\mathbf{3}$ & $\begin{array}{l}\text { Lombok, NTB, } \\
\text { Jakarta }\end{array}$ & 3 & 8.82 \\
$\mathbf{4}$ & Gorontalo & 1 & 2.94 \\
& Unidentified & 3 & 8.82 \\
\hline
\end{tabular}

South Sulawesi students are the biggest population as the subjects of research. It is shown on the data that a lot of speakers make filler in conversation process. Speakers from that region spoke without hesitation about themselves. Besides, Hasanuddin University is located in South Sulawesi where the researcher carried out the data. 
Table 5. The Frequency in Using Arabic

\begin{tabular}{llll}
\hline No & Frequency & R & \% \\
\hline $\mathbf{1}$ & Often & 11 & 32.35 \\
$\mathbf{2}$ & Seldom & 19 & 55.88 \\
$\mathbf{3}$ & Sometimes & 4 & 11.77 \\
$\mathbf{4}$ & Always & 0 & 0 \\
\hline
\end{tabular}

Respondents seldom use Arabic as the Arabic is very difficult to them. As explained in background Arabic is derivative language which have accusative and soon. If speaker wants to mix it, they need to have an adequate vocabulary and comprehending concerning grammar (nahwu).

Table 5. Place of respondents in Using Arabic?

\begin{tabular}{|c|c|c|c|}
\hline No. & Place & $\mathbf{R}$ & $\%$ \\
\hline 1 & Worship & 23 & 41.07 \\
\hline 2 & Class & 16 & 28.57 \\
\hline 3 & Arabic community & 15 & 26.79 \\
\hline 4 & In SMS & 2 & 3.57 \\
\hline
\end{tabular}

Since Arabic is lingua franca of moslem, it is arguable that Arabic usually occurs in worship and ceremonial activity.

Table 6. Respondent's Addressees

\begin{tabular}{llcc}
\hline No & Interlocutors & R & \% \\
\hline $\mathbf{1}$ & Classmate & 24 & 32.43 \\
\hline $\mathbf{2}$ & Dormmate & 10 & 13.51 \\
$\mathbf{3}$ & Family & 5 & 6.75 \\
$\mathbf{4}$ & Lecturers & 13 & 17.56 \\
$\mathbf{5}$ & $\begin{array}{l}\text { Friends in Arabic } \\
\text { community }\end{array}$ & 13 & 17.56 \\
$\mathbf{6}$ & $\begin{array}{l}\text { Pesantren } \\
\text { (boarding school) } \\
\text { mates }\end{array}$ & 9 & 12.16 \\
\hline & & & \\
\hline
\end{tabular}

Researcher expected that Arabic would frequently get used in daily activities, yet the data showed Arabic usually spoken in classroom with classmate. As the students' intentions are to elevate their knowledge, they should to practice their language yet it could be explained as the matter of fact that they shy to practice outside the classroom due to afraid stigmatized as pious person.

Table 7. The Level of The Address Helping the Respondents' Language Skill

\begin{tabular}{clcc}
\hline No & $\begin{array}{c}\text { Do They Improve Your } \\
\text { Arabic? }\end{array}$ & R & $\%$ \\
\hline $\mathbf{1}$ & Yes & 25 & 65.78 \\
$\mathbf{2}$ & No, they are not & 5 & 13.15 \\
$\mathbf{3}$ & Sometimes & 8 & 21.05 \\
\hline
\end{tabular}

Respondents addressee are students, so it is unavoidance interaction to practice Arabic while at the same time they are discussing concerning class task and Arabic culture and topography interchangeably.

Table 8. Speakers Speak Arabic in Middle Frequency

\begin{tabular}{|c|c|c|c|}
\hline No & The Reasons & $\mathbf{R}$ & $\%$ \\
\hline 1 & $\begin{array}{l}\text { Not accordance in } \\
\text { Indonesian }\end{array}$ & 6 & 10 \\
\hline 2 & Arabic more efficient & 7 & 11.66 \\
\hline 3 & $\begin{array}{l}\text { The Arabic technical } \\
\text { term was well known } \\
\text { (syukran, mā, limadza, } \\
\text { etc) }\end{array}$ & 7 & 11.66 \\
\hline 4 & $\mathrm{C}-\mathrm{S}$ is their habit & 13 & 21.66 \\
\hline 5 & $\begin{array}{l}\text { Indonesian-Arabic } \mathrm{C}-\mathrm{S} \\
\text { more polite }\end{array}$ & 2 & 3.33 \\
\hline 6 & $\begin{array}{l}\text { The situation is formal } \\
\text { and informal }\end{array}$ & 4 & 6.66 \\
\hline 7 & $\begin{array}{l}\text { The topic of } \\
\text { conversation }\end{array}$ & 2 & 3.33 \\
\hline 8 & $\begin{array}{l}\text { Honour to the } \\
\text { interlocution }\end{array}$ & 8 & 13.33 \\
\hline 9 & Repetition & 1 & 1.66 \\
\hline
\end{tabular}




\begin{tabular}{|llll}
\hline 10 & $\begin{array}{l}\text { Keep conversation still } \\
\text { go on }\end{array}$ & 9 & 15 \\
11 & $\begin{array}{l}\text { To soften request or } \\
\text { command }\end{array}$ & 1 & 1.66 \\
\hline
\end{tabular}

Reason of speaker to switch their language to Arabic is because of habit. One of the most wellknown proverbs is "the more you practice the more you perfect". It is one of the principles to upgrade speaking skill when studying foreign language is keep practicing by talking.

Table 9. Speakers' Motivation

\begin{tabular}{lllc}
\hline No & The Motivation & R & \% \\
\hline $\mathbf{1}$ & $\begin{array}{l}\text { To activate their } \\
\text { vocabularies }\end{array}$ & 28 & 77.77 \\
$\mathbf{2}$ & Arabic more polite & 4 & 11.11 \\
$\mathbf{3}$ & $\begin{array}{l}\text { To honour their } \\
\text { interlocutor }\end{array}$ & 2 & 5.55 \\
$\mathbf{4}$ & To quote & 2 & 5.55 \\
\hline
\end{tabular}

Language learning traditional method is three methods. One of it is equipped the learner with vocabularies before speak out loud. Therefore, activate vocabularies means practicing while memorizing and practicing grammar.

Table 10. Speakers' Difficulties

\begin{tabular}{|c|c|c|c|}
\hline No & The Difficulty & $\mathbf{R}$ & $\%$ \\
\hline 1 & To define the last of words & 15 & 37.5 \\
\hline 2 & $\begin{array}{l}\text { Lack of communication with } \\
\text { friends }\end{array}$ & 17 & 42.5 \\
\hline 3 & Lack of vocab & 3 & 7.5 \\
\hline 4 & Lack to activate & 2 & 5 \\
\hline 5 & $\begin{array}{l}\text { The grammar of Arabic is so } \\
\text { many }\end{array}$ & 1 & 2.25 \\
\hline 6 & $\begin{array}{l}\text { Not yet expert to produce } \\
\text { sentence }\end{array}$ & 1 & 2.25 \\
\hline 7 & Least confidence & 1 & 2.25 \\
\hline
\end{tabular}

Speakers' difficulties are lack of communication, as saying "practice makes perfect" is fit here. There are four basic skill in learning language, listening, speaking, reading, and writing. Listening and speaking is badly important in process of practicing foreign language since Arabic is not even the second language of the learners.

\section{CONCLUSION AND SUGESTION}

\section{Conclusion}

Based on the previous chapter, it can be concluded that there are three points which become the main aim of this discussion in this reasearch. They are the result from investigation in the types of Indonesian-Arabic C-S, Arabic syntactic words categories, and the result of investigation in reason of Indonesian-Arabic code-switching.

The dominant types of Indonesian-Arabic c-s is inter-sentencial c-s comprising 25 corpuses with $50 \%$ of the data. Second, intra-phrase comprising 8 corpuses with $16 \%$ of the data. Third, intrasentencial c-s comprising 5 corpuses with $10 \%$ of the data. Fourth, intra-lexical comprising 4 corpuses with $8 \%$ of the data. Fifth, tag-switching comprising 3 corpuses with $6 \%$ of the data. Sixth, there are two types of Indonesian-Arabic code-switching that are intra-clause and inter-clause code-switching each type of these switchings comprising 2 corpuses with $4 \%$ of the data.

In term of Arabic syntactic words shows that noun is the most dominant word which is switch by the lecturer and students in the class comprising $38.41 \%$ of the data. Second, noun phrase comprising $32.31 \%$ of the data. Third, verb phrase comprising $17.07 \%$ of the data. Fourth, there are two Arabic syntactic words categories have the same corpuses, verb and adverb each of it comprising $4.88 \%$ of the data. Fifth, noun clause comprising with $2.44 \%$ of the data.

In term of reason of indonesian-Arabic c-s, the repetition to clarify and emphasize the message or message reiteration comprising with $20.83 \%$ of the data. Second, to nativise the Indonesian-Arabic c-s and intention clarifying speech content for interlocutor each of it comprising 16.675 of the data. Third, to quote Arabic termiologises or expression comprising with $14.58 \%$. Fourth, topic have been talked comprising with $10.41 \%$ of the data. Fifth, interjection comprising $8.33 \%$ of the data. Sixth, to soften or strengthen request or command. Seventh, 
there are four reasons have same reasons they are play with Arabic phoneme, to exclude another poeple when a comment intended for limited audience and expressing group identity and to gain attention. Each of that reason consist of $2.08 \%$ of the data.

\section{Suggestion}

Suggestion is idea, plan, etc, that you mean for somebody to think about. For the next research is suggested to investigate the reason of codeswitching outside the class room and the types of Arabic-Indonesian code-switching (Arabic based).

\section{REFERENCES}

Cakrawarti, D.A. 2011. Analysis of Code Switching And Code Mixing In The Teenlit Canting Cantiq By Dyan Nuranindya. http://eprints.undip.ac.id/27046/2/ANALYSIS _OF_CODE_SWITCHING_AND_CODE_M IXING_IN_THE_TEENLIT_CANTING_CA NTIQ_BY_DYAN_NURANINDYA.pdf accessed on 10 November 2011.
Chaer, Abdul and Leonie, A. 2010. Sosiolinguistik: Perkenalan Awal. Ed. Rev. Jakarta; Rineka Cipta.

Fadhilah, 2010. The Functions of JapaneseIndonesian Code-Switching. Unpublished thesis of Hasanuddin University.

Gumperz, J.J. 1982. Discourse Strategies. Cambridge University Press: Cambridge.

Iriyati. 2008. Code-Switching in MTV Ampuh on Global TV. Unpublished thesis of Hasanuddinn University.

Pidarmawaty, S. 2005. "The use of Code-Mixing by Malaysia Students' Community”. Unpulished thesis of Hasanuddin University.

Rosdiana, 2011. Code-switching used in Prambors Radio Programs. Unpublished thesis of Hasanuddin University.

Wardhaugh, R. 1987. An introduction to sociolinguistics. Oxford: Basic Blackwell.

Yassi, Hakim, A. 2003. Code switching as a communication strategy in IndonesianEnglish bilingual discourses: A congruencefunctional approach to IndonesianEnglish code switching. Unpublished dissertation of Hasanuddin University. 